\title{
Safety and utility of kyphoplasty prior to spine stereotactic radiosurgery for metastatic tumors: a clinical and dosimetric analysis
}

\author{
Ori Barzilai, MD, ${ }^{1}$ Natalie DiStefano, ${ }^{1}$ Eric Lis, MD, ${ }^{2}$ Yoshiya Yamada, MD, ${ }^{3}$ \\ D. Michael Lovelock, PhD, ${ }^{4}$ Andrew N. Fontanella, PhD, ${ }^{4}$ Mark H. Bilsky, MD, ${ }^{1,5}$ and \\ Ilya Laufer, MD ${ }^{1,5}$
}

Departments of ${ }^{1}$ Neurosurgery, ${ }^{2}$ Radiology, ${ }^{3}$ Radiation Oncology, and ${ }^{4}$ Medical Physics, Memorial Sloan Kettering Cancer
Center; and ${ }^{5}$ Department of Neurological Surgery, Weill Cornell Medical College, New York, New York

OBJECTIVE The aim of this study was to evaluate the safety and efficacy of kyphoplasty treatment prior to spine stereotactic radiosurgery (SRS) in patients with spine metastases.

METHODS A retrospective review of charts, radiology reports, and images was performed for all patients who received SRS (single fraction; either standalone or post-kyphoplasty) at a large tertiary cancer center between January 2012 and July 2015. Patient and tumor variables were documented, as well as treatment planning data and dosimetry. To measure the photon scatter due to polymethyl methacrylate, megavolt photon beam attenuation was determined experimentally as it passed through a kyphoplasty cement phantom. Corrected electron density values were recalculated and compared with uncorrected values.

RESULTS Of 192 treatment levels in 164 unique patients who underwent single-fraction SRS, 17 (8.8\%) were treated with kyphoplasty prior to radiation delivery to the index level. The median time from kyphoplasty to SRS was 22 days. Four of 192 treatments $(2 \%)$ demonstrated local tumor recurrence or progression at the time of analysis. Of the 4 local failures, 1 patient had kyphoplasty prior to SRS. This recurrence occurred 18 months after SRS in the setting of widespread systemic disease and spinal tumor progression. Dosimetric review demonstrated a lower than average treatment dose for this case compared with the rest of the cohort. There were no significant differences in dosimetry analysis between the group of patients who underwent kyphoplasty prior to SRS and the remaining patients in the cohort. A preliminary analysis of polymethyl methacrylate showed that dosimetric errors due to uncorrected electron density values were insignificant.

CONCLUSIONS In cases without epidural spinal cord compression, stabilization with cement augmentation prior to SRS is safe and does not alter the efficacy of the radiation or preclude physicians from adhering to SRS planning and contouring guidelines.

https://thejns.org/doi/abs/10.3171/2017.5.SPINE1746

KEY WORDS kyphoplasty; stereotactic radiosurgery; spine SRS; local control; spine tumors; oncology

S PINAL metastases are present in approximately $30 \%$ of oncology patients, ${ }^{22}$ and with improved diagnostics and targeted therapies, the incidence of spine tumors is expected to increase. The morbidity associated with spinal metastases includes severe pain associated with instability and neurological injury from spinal cord or nerve root compression. ${ }^{17}$ The goals of treatment for spinal metastases include treatment of the local tumor, restoration of spinal stability, and palliation of symptoms. Stereotactic radiosurgery (SRS) has the ability to produce a sharp dose falloff at tumor margins and therefore allows delivery of a high radiation dose to the tumor while sparing nearby critical normal structures, particularly the spinal cord. Evidence shows that SRS is an effective primary or salvage treatment for spinal metastases. ${ }^{1,13,17,20,30}$

Mechanical instability causes pain and discomfort.

ABBREVIATIONS CTV = clinical treatment volume; GTV = gross tumor volume; PMMA = polymethyl methacrylate; PTV = planned treatment volume; SINS = spinal instability neoplastic score; SRS = stereotactic radiosurgery.

SUBMITTED January 10, 2017. ACCEPTED May 12, 2017

INCLUDE WHEN CITING Published online November 3, 2017; DOI: 10.3171/2017.5.SPINE1746. 
Treatment of mechanical instability prior to SRS can be beneficial in facilitating radiotherapy and providing timely pain relief. Kyphoplasty has proven to be an effective method of pain reduction in cases of tumor-related compression fractures..$^{12,31}$ Kyphoplasty prior to radiosurgery has been described as an effective treatment strategy $\mathrm{y}^{14}$; however, 2 cases of tumor progression due to suspected extravasation after pre-SRS kyphoplasty have been reported. ${ }^{9}$ Displacement of tumor into the epidural space may preclude the delivery of a cytotoxic tumoral dose within the constraints of spinal cord tolerance. Moreover, data regarding the effect of SRS on polymethyl methacrylate (PMMA) are lacking.

Therefore, we examined whether treatment of mechanically unstable vertebral compression fractures with kyphoplasty prior to SRS is a risk factor for post-SRS tumor recurrence in a series of patients who underwent single-fraction SRS. In addition, we performed a dosimetry analysis to evaluate treatment differences.

\section{Methods}

This is a retrospective evaluation of patients who underwent single-fraction SRS for osseous tumors of the spine between January 2012 and July 2015. Demographic and tumor data included age, sex, tumor histology, and tumor location. Treatment parameters included dosimetry, fractionation schedule, presence or absence of kyphoplasty prior to SRS, time from kyphoplasty to SRS, and local tumor control. Patients were included only if they received $24 \mathrm{~Gy}$ in a single fraction to the reported treatment area.

\section{Kyphoplasty Procedure}

The technique for percutaneous cement augmentation at our institution has been described elsewhere..$^{20}$ In brief, patients were placed under general anesthesia, and either fluoroscopy or CT-based navigation was used to determine locations for skin incisions and bony penetration. A Jamshidi needle was advanced to the vertebral body using a transpedicular or parapedicular trajectory. A bone tamp was inserted. Under fluoroscopic guidance, the bone tamp was inflated to create a cavity in the vertebral body. PMMA with a barium opacifier was injected with intermittent fluoroscopic confirmation of cement placement, and signs of extravasation were examined. The needle was removed and final anterior-posterior and lateral radiographs were obtained.

\section{SRS Protocol}

A detailed description of our SRS protocol has been described. ${ }^{18,32}$ All volumes were contoured according to the International Spine Radiosurgery Consortium guidelines. ${ }^{8}$ The gross tumor volume (GTV) was contoured to account for radiologically demonstrated tumor, including epidural and paraspinal extension. To incorporate suspected microscopic disease, the clinical treatment volume (CTV) was contoured to include all bone marrow adjacent to the GTV. The planned treatment volume (PTV) was expanded around the CTV and modified to exclude the dural margin and adjacent critical structures. Dose distributions were planned with either an in-house or commercially available treatment planning system. Treatments were delivered with intensity modulated radiotherapy using 7-9 non-coplanar beams or volumetric arc therapy. The prescription dose was 24 Gy delivered in a single fraction. Treatments were delivered using a linear accelerator (Trilogy or TrueBeam, Varian Medical Systems).

\section{Electron Density Measurement}

A PMMA phantom (Kyphon, Medtronic) was created at our institutional instrument shop. Megavolt beam attenuation as it passed through a kyphoplasty cement phantom was measured. The electron density of the cement in a CT scan of the phantom was adjusted such that the computed attenuation matched the measured attenuation. The corrected electron density values were then substituted into the treatment planning system (Eclipse, Varian Medical Systems) for a number of patients who had received kyphoplasty procedures prior to radiation therapy. Dose to the cord and PTV were recalculated and compared with uncorrected values.

\section{Patient Evaluation}

Patients were evaluated clinically during the immediate posttreatment period, and both clinically and radiologically at 3- to 6-month intervals or sooner if symptomatically indicated. Patient charts and images were reviewed for any signs of local treatment failure.

Statistical analysis was performed using IBM SPSS Statistics version 24.0 (IBM Corp.). The Student t-test was used to evaluate potential differences in dosimetry between the group of patients who were treated with kyphoplasty prior to SRS and the rest of the cohort.

This study was approved by our institutional review board with a waiver of informed consent.

\section{Results}

Seventeen patients underwent single-level kyphoplasty for symptomatic, pathological burst or compression fractures prior to SRS. The median time from kyphoplasty to SRS was 22 days (range 12-135 days). The median time to obtain a CT myelogram used for simulation was 9 days (range 3-103 days). Patients who underwent kyphoplasty had a median spinal instability neoplastic score (SINS) of 10 (range 9-11), defined as potentially unstable.

Overall, 192 levels were treated in 164 patients, of whom $106(65 \%)$ were male. Patient demographic and tumor histology data are summarized in Table 1. Of 192 treatment levels, 188 (98\%) had durable local control throughout the follow-up period. Four patients had documented progression of disease at the previously treated level (Table 2).

Of the cases involving local failures, 1 patient (5.8\%) treated with kyphoplasty prior to SRS had evidence of local recurrence on follow-up imaging. This patient had a T-10 prostate metastasis and presented with severe, nonradiating, axial-load back pain. MRI demonstrated a T-1 hypointense lesion with minimal epidural impingement (epidural spinal cord compression Grade $1 b^{4}$ ) and a vertebral compression fracture with $<50 \%$ loss of height. He underwent T-10 kyphoplasty with significant reduction of pain. Kyphoplasty was followed by SRS to T-10. Initially, 
TABLE 1. Patient and tumor characteristics

\begin{tabular}{|c|c|}
\hline Variable & No. $(\%)$ \\
\hline Total no. of spine SRS cases screened, 1/2012-7/2015 & 192 \\
\hline Total no. of unique patients screened & 164 \\
\hline \multicolumn{2}{|l|}{ Age at SRS, yrs } \\
\hline Mean & 60 \\
\hline Range & $24-86$ \\
\hline \multicolumn{2}{|l|}{ Sex } \\
\hline Female & $58(35)$ \\
\hline Male & $106(65)$ \\
\hline \multicolumn{2}{|l|}{ Tumor pathology for pre-SRS kyphoplasty group } \\
\hline RCC & $6(36)$ \\
\hline Lung & $3(18)$ \\
\hline Sarcoma & $4(22)$ \\
\hline Other & $4(24)$ \\
\hline \multicolumn{2}{|l|}{ Treatment characteristic } \\
\hline Pre-SRS kyphoplasty & $23(13)$ \\
\hline Kyphoplasty to the SRS level & $17(10)$ \\
\hline Kyphoplasty to non-SRS level & $6(3)$ \\
\hline \multicolumn{2}{|l|}{ Pre-SRS kyphoplasty location } \\
\hline Thoracic & $8(47)$ \\
\hline Lumbar & $9(53)$ \\
\hline \multicolumn{2}{|l|}{ Time from kyphoplasty to SRS, days } \\
\hline Mean & 22 \\
\hline Range & $12-135$ \\
\hline \multicolumn{2}{|l|}{ Follow-up, mos $(n=164)$} \\
\hline Mean & 11.4 \\
\hline Range & $0-43.5$ \\
\hline Local recurrence in screened population & $4 / 192(2)$ \\
\hline Local recurrence in kyphoplasty pre-SRS & $1 / 17(5.8)$ \\
\hline
\end{tabular}

RCC $=$ renal cell carcinoma.

Values are numbers (\%) of cases unless otherwise indicated.

good local control was noted. Approximately 18 months after treatment, the patient developed widespread systemic metastatic disease with multiple new bone lesions in the spine, ribs, and pelvis. The T-10 metastasis demonstrated progression with new involvement of adjacent segments (i.e., T-9 and T-11) and epidural involvement with moderate epidural compression (epidural spinal cord compression Grade 2), more prominent at T-11. Because of this progression with new high-grade spinal cord compression at a previously irradiated site, he underwent separation surgery followed by reirradiation.

Typically, when the vertebral body is infiltrated, the entire vertebral body is contoured in accordance with the International Spine Radiosurgery Consortium consensus guidelines ${ }^{8}$ while disregarding the "bone cement." There were no cases in which kyphoplasty caused significant extravasation of PMMA into the epidural space necessitating open decompression or precluding the ability to deliver a cytotoxic dose.

All patients received 24 Gy in a single treatment fraction. Dosimetry analysis was performed to evaluate differences between the group of patients who underwent kyphoplasty prior to SRS and the rest of the cohort (Table 2). No significant differences were found between the groups with or without kyphoplasty with regard to the GTV D95 (dose that covers 95\% of the GTV) (mean 2295 vs 2353 cGy, respectively; $\mathrm{p}=0.44$ ) or the PTV D95 (dose that covers 95\% of the PTV) (mean 2234 vs 2260 cGy, respectively; $\mathrm{p}=0.60$ ). In addition, no significant differences were found in other dosimetric variables, including GTV, GTV V95 (percentage of GTV covered by $95 \%$ of the prescribed dose), PTV, PTV V95 (percentage of PTV covered by $95 \%$ of the prescribed dose), and PTV D05 (dose that covers $5 \%$ of the PTV).

With electron densities corrected, preliminary analysis has shown that dosimetric errors due to uncorrected electron density values were insignificant, producing deviations $\leq 1 \%$ for maximum, minimum, or mean doses to PTVs and organs at risk.

\section{Discussion}

Stereotactic radiosurgery has improved over the last decade due to technical advances in imaged-guided radiotherapy and improvements in the precision of radiotherapy delivery with the various forms of intensity-modulated radiotherapy or volumetric arc therapy that are available..$^{29}$ Large series have been described confirming the efficacy of SRS in the treatment of osseous spinal tumors. ${ }^{13,20,30}$

Palliation of symptoms and pain management are important goals of treatment in patients with metastatic osseous lesions. In one series of patients with spine tumors who underwent SRS, Puvanesarajah et al. ${ }^{24}$ determined that prior radiation therapy and the degree of epidural tumor extension were poor prognostic factors for pain palliation after spine stereotactic body radiation therapy. Of the 99 patients, 6 had undergone vertebroplasty prior to SRS and 4 after treatment. No data were provided regarding

TABLE 2. Dosimetry analysis of SRS database versus pre-SRS kyphoplasty patients

\begin{tabular}{lccccccc}
\hline \multicolumn{1}{c}{ Variable } & $\begin{array}{c}\text { Mean GTV, } \\
\mathrm{cm}^{3}\end{array}$ & $\begin{array}{c}\text { Mean GTV } \\
\text { D95 }\end{array}$ & $\begin{array}{c}\text { Mean GTV } \\
\text { V95 }\end{array}$ & $\begin{array}{c}\text { Mean PTV, } \\
\mathrm{cm}^{3}\end{array}$ & $\begin{array}{c}\text { Mean PTV } \\
\text { D95 }\end{array}$ & $\begin{array}{c}\text { Mean PTV } \\
\text { D05 }\end{array}$ & $\begin{array}{c}\text { Mean PTV } \\
\text { V95 }\end{array}$ \\
\hline SRS data set & $19.78(\mathrm{n}=161)$ & $2295.11(\mathrm{n}=161)$ & $123.28(\mathrm{n}=160)$ & $109.23(\mathrm{n}=166)$ & $2234.20(\mathrm{n}=171)$ & $2639.67(\mathrm{n}=171)$ & $94.38(\mathrm{n}=171)$ \\
\hline Pre-SRS kyphoplasty & $23.74(\mathrm{n}=17)$ & $2353.12(\mathrm{n}=16)$ & $96.65(\mathrm{n}=16)$ & $75.07(\mathrm{n}=17)$ & $2260.11(\mathrm{n}=17)$ & $2663.52(\mathrm{n}=17)$ & $95.51(\mathrm{n}=17)$ \\
\hline p value (2-tailed) & 0.515 & 0.449 & 0.667 & 0.736 & 0.608 & 0.674 & 0.285 \\
\hline
\end{tabular}

GTV D95 = dose that covers $95 \%$ of the GTV; GTV V95 = percentage of GTV covered by $95 \%$ of the prescribed dose; PTV D05 = dose that covers $5 \%$ of the PTV; PTV D95 = dose that covers $95 \%$ of the PTV; PTV V95 = percentage of PTV covered by $95 \%$ of the prescribed dose. 
the contouring and treatment plan for these specific patients; however, there were no cases of radiation-induced spinal cord myelopathy and a 7.0\% risk for de novo vertebral compression fractures, consistent with rates reported in prior studies (range 6.6\%-11.0\%). 710,28

There is no accepted paradigm regarding the use of kyphoplasty prior to SRS. It is currently accepted that patients with radiosensitive tumors and no evidence of myelopathy can be treated effectively with conventional external beam radiation therapy regardless of the degree of epidural spinal cord compression. ${ }^{15}$ Patients with lowgrade epidural spinal cord compression and radioresistant tumors can be effectively treated with SRS. It has recently been shown that SRS can achieve high rates of local control regardless of tumor histology because local control rates rely on treatment dose and are histology independent. ${ }^{33}$ On the other hand, surgical stabilization followed by decompression is recommended in patients with radioresistant tumors in the setting of high-grade spinal cord compression. ${ }^{3}$ Further, spinal instability is an independent indication for intervention regardless of the radiosensitivity of the tumor or degree of spinal cord compression. Therefore, patients with mechanical instability due to radioresistant tumors, without compression of the spinal cord, are excellent candidates for kyphoplasty followed by SRS.

The SINS,$^{11}$ which was generated by the Spine Oncology Study Group, is a powerful tool to aid general practitioners in deciding when to refer a patient to a spine surgeon. The SINS also assists spine surgeons in systematically categorizing vertebral fractures into 3 categories: 1) stable, 2) potentially unstable, and 3) unstable. Patients who present with mechanical, axial back pain ${ }^{5}$ without significant fracture extension into posterior elements, usually classified as potentially unstable according to the SINS, often benefit from percutaneous vertebral cement augmentation. ${ }^{2,28}$ More than a decade ago, Gerszten et al. described the combined kyphoplasty and spinal radiosurgery treatment paradigm. They reported that the combination was clinically effective in patients with pathological fractures..$^{14}$ In the current series, the median SINS was 10 for patients who underwent kyphoplasty prior to SRS, indicating potential instability; however, all patients treated experienced severe mechanical pain resulting from a burst or compression fracture.

Treatment planning, for SRS in general and for spine SRS in particular, has evolved tremendously. Although the optimal plan, dosimetry, and fractionation are often debatable, vast data for SRS planning exist with suggested guidelines. In 2012, the International Spine Radiosurgery Consortium published consensus guidelines for target volume definition in spine SRS, paving the road for standardized nomenclature and dosimetric reporting for spine SRS. ${ }^{8}$ SRS practice guidelines were developed and written collaboratively by the American College of Radiology and the American Society of Therapeutic Radiology and Oncology. ${ }^{23}$ Similarly, the Canadian Association of Radiation Oncology published practice guidelines for lung, liver, and spine stereotactic body radiotherapy. ${ }^{26}$ In 2013, safe practice guidelines using a logistic regression model were published, yielding estimates for the probability of radiation-induced myelopathy specific to stereotactic body radiation therapy. ${ }^{27}$ Recently, contouring guidelines have been suggested in the postoperative setting. ${ }^{25}$ None of the guidelines or publications specifically address treatment planning for tumor control in a vertebra treated with PMMA or other cement-like materials.

Cruz et al. raised concerns regarding the possible role of kyphoplasty in local spread of metastatic disease. ${ }^{9}$ In their article, 2 cases of suspected tumor extravasation following cement augmentation are described, prompting reevaluation of this treatment paradigm. These data justified paying close attention to the post-kyphoplasty tumor morphology when planning spine SRS.

We reviewed our experience with patients who experienced tumor-related mechanical back pain, had minimal or no epidural spinal cord compression, had SINS consistent with instability or potential instability, and underwent kyphoplasty prior to SRS. As shown in our current series, 17 cases required cement augmentation for pain relief prior to SRS. Spine SRS studies have reported that intrafraction motion on the order of millimeters can significantly affect the actual dose delivered to the spinal cord. ${ }^{19} \mathrm{We}$ hypothesize that this pain relief makes the treatment more tolerable for patients and that it may also reduce interfraction movement, resulting in shorter and more accurate treatments.

Data on the effect of PMMA on the radiation efficacy and safety in the era of SRS are lacking, yet interest is growing. ${ }^{16}$ Historical studies showed that the clinical use of gamma radiation on neoplastic bone is not affected by the presence of PMMA..$^{21}$ Bariated material attenuates kilovoltage photons to a higher degree than tissues due to the relatively high K-edge of barium $(37.4 \mathrm{keV})$. This may lead to the overestimation of electron densities for kyphoplasty cement in patient CT scans. Consequentially, dosimetric calculations that rely on these electron densities may be inaccurate when megavoltage beams propagate through such material. To assess the degree of this inaccuracy, we empirically measured megavolt beam attenuation as it passed through a kyphoplasty cement phantom, thus deriving a more accurate estimate of the electron density of the material. The corrected electron density values were then substituted into the treatment planning system for 3 patients who had received kyphoplasty prior to radiation therapy. Dose to the spinal cord and PTV were recalculated and compared with uncorrected values. Details of this analysis will be presented in an upcoming technical report; however, preliminary analysis has shown that dosimetric errors due to uncorrected electron density values were insignificant, producing deviations $\leq 1 \%$ for maximum, minimum, or mean doses to PTVs and organs at risk.

Our practice is to contour the CTV and PTV in accordance with consensus guidelines, ${ }^{8,25}$ regardless of the injected PMMA (Fig. 1). The dosimetry analysis presented herein demonstrated that there were no significant differences in SRS planning between patients with or without cement augmentation prior to SRS. In this cohort, 4 patients had local recurrence following singlefraction, 24-Gy SRS to a metastatic spinal lesion. One of these patients underwent kyphoplasty prior to radiation 

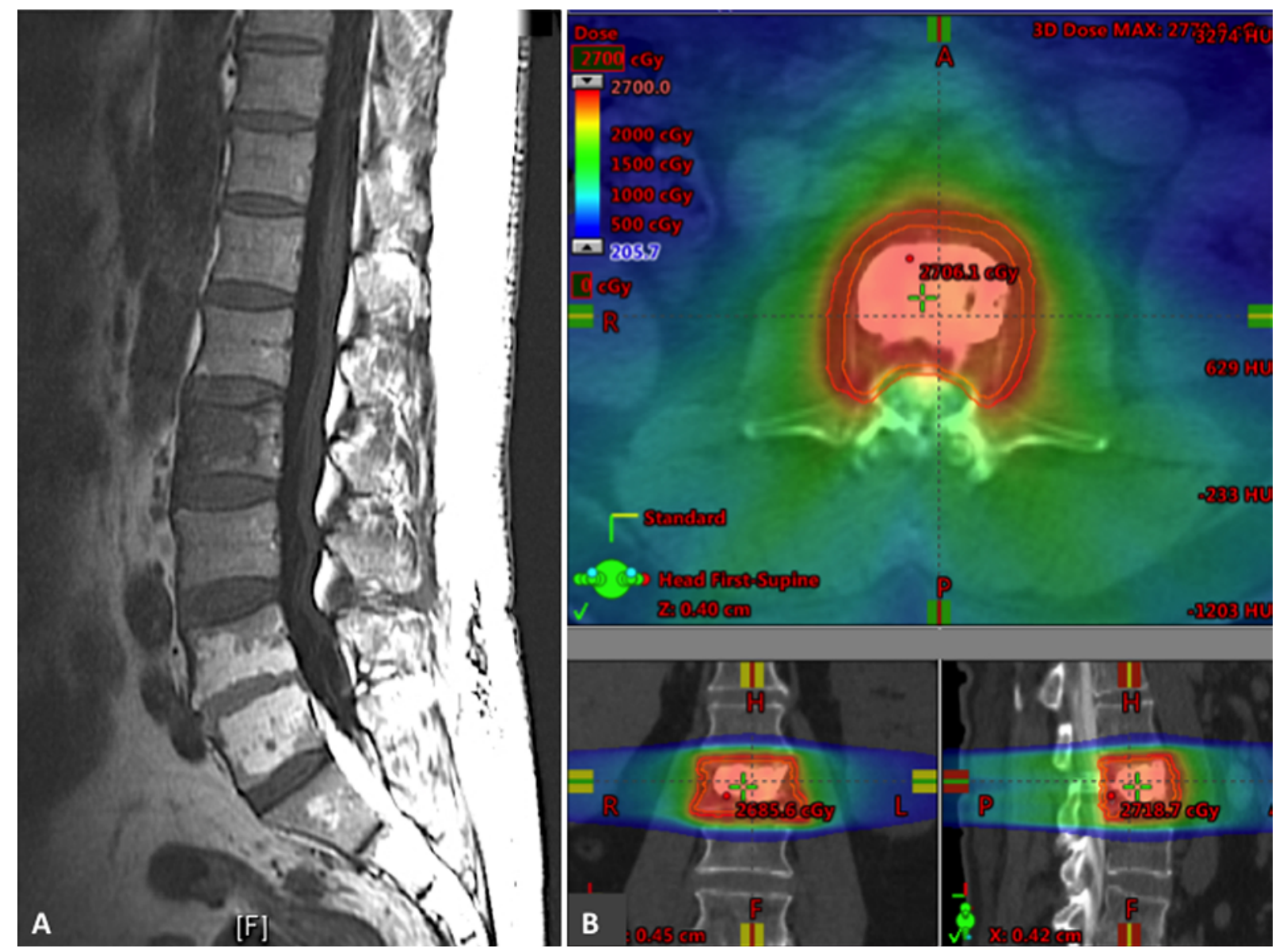

FIG. 1. Treatment with SRS to a previously cement-augmented vertebra. A: T1-weighted MR image demonstrating an L-2 hypointense lesion. B: Dose watch analysis for SRS, including the bone cement and avoiding radiation to nearby unaffected vital structures.

treatment. At the time of local recurrence, this patient had developed widespread metastases with new lesions in his ribs, pelvis, and spine. The thoracic levels adjacent to the previously treated levels had become infiltrated with tumor, and epidural spinal cord compression was evident at levels T9-10.

This patient had previously received radiation treatment to this area and at the time of the investigated treatment (kyphoplasty followed by SRS) was treated with salvage radiosurgery with a planned dose of $24 \mathrm{~Gy}$ in a single fraction. However, a review of this patient's dosimetry data demonstrated that this patient had actually received a smaller radiation dose than average (D95 $=1919$ cGy compared with D95 $=2353$ cGy [the mean of the cohort]) due to dose constraints from previous radiation treatment.

Dose insufficiency to even small volumes of the target, as indicated by D95, has been shown to be strongly correlated with local failure; ${ }^{6,17}$ thus the progression in this patient can probably be attributed to the aggressive biological behavior of this particular disease and in part to the lower radiation dosage. Be that as it may, this local failure is probably unrelated to the kyphoplasty. There were no cases documented where treatment with kyphoplasty ul- timately altered the treatment plan, dose, or timing of the SRS or necessitated surgery prior to SRS.

We recognize the inherent flaws of this analysis as a retrospective review. The sample size of the cohort of patients who received a single-fraction $24-G y$ SRS is adequate. However, the number of patients treated with kyphoplasty prior to SRS is small; therefore, it is impossible to draw firm conclusions or to achieve statistical significance. To note, the data set of interest for this analysis included the 17 patients who underwent kyphoplasty prior to SRS. The larger group of patients serves as a control, single-fraction SRS group. The rationale was to validate that planning and contouring for patients treated with or without kyphoplasty are similar, and thus the dosimetric analysis between the groups was performed. We present a single case of treatment failure of SRS following kyphoplasty that cannot be directly associated at this time, and firm conclusions should not be made.

\section{Conclusions}

Pain management with cement augmentation prior to SRS seems to be safe. It probably does not alter the radiation efficacy, nor should it preclude physicians from adher- 
ing to SRS planning and contouring guidelines. The possible hazard of tumor extravasation following kyphoplasty, although not observed in this series, must still be closely monitored. Further large-scale studies determining the effect of vertebral cement augmentation on spine SRS are needed to improve treatment paradigms.

\section{Acknowledgments}

This research was funded in part through the NIH/NCI Cancer Center Support Grant P30 CA008748.

\section{References}

1. Bate BG, Khan NR, Kimball BY, Gabrick K, Weaver J: Stereotactic radiosurgery for spinal metastases with or without separation surgery. J Neurosurg Spine 22:409-415, 2015

2. Berenson J, Pflugmacher R, Jarzem P, Zonder J, Schechtman $\mathrm{K}$, Tillman JB, et al: Balloon kyphoplasty versus nonsurgical fracture management for treatment of painful vertebral body compression fractures in patients with cancer: a multicentre, randomised controlled trial. Lancet Oncol 12:225-235, 2011

3. Bilsky MH, Laufer I, Burch S: Shifting paradigms in the treatment of metastatic spine disease. Spine (Phila Pa 1976) 34 (22 Suppl):S101-S107, 2009

4. Bilsky MH, Laufer I, Fourney DR, Groff M, Schmidt MH, Varga PP, et al: Reliability analysis of the epidural spinal cord compression scale. J Neurosurg Spine 13:324-328, 2010

5. Bilsky MH, Shannon FJ, Sheppard S, Prabhu V, Boland PJ: Diagnosis and management of a metastatic tumor in the atlantoaxial spine. Spine (Phila Pa 1976) 27:1062-1069, 2002

6. Bishop AJ, Tao R, Rebueno NC, Christensen EN, Allen PK, Wang XA, et al: Outcomes for spine stereotactic body radiation therapy and an analysis of predictors of local recurrence. Int J Radiat Oncol Biol Phys 92:1016-1026, 2015

7. Boehling NS, Grosshans DR, Allen PK, McAleer MF, Burton AW, Azeem S, et al: Vertebral compression fracture risk after stereotactic body radiotherapy for spinal metastases. J Neurosurg Spine 16:379-386, 2012

8. Cox BW, Spratt DE, Lovelock M, Bilsky MH, Lis E, Ryu $S$, et al: International Spine Radiosurgery Consortium consensus guidelines for target volume definition in spinal stereotactic radiosurgery. Int J Radiat Oncol Biol Phys 83:e597-e605, 2012

9. Cruz JP, Sahgal A, Whyne C, Fehlings MG, Smith R: Tumor extravasation following a cement augmentation procedure for vertebral compression fracture in metastatic spinal disease. J Neurosurg Spine 21:372-377, 2014

10. Cunha MV, Al-Omair A, Atenafu EG, Masucci GL, Letourneau D, Korol R, et al: Vertebral compression fracture (VCF) after spine stereotactic body radiation therapy (SBRT): analysis of predictive factors. Int J Radiat Oncol Biol Phys 84:e343-e349, 2012

11. Fisher CG, DiPaola CP, Ryken TC, Bilsky MH, Shaffrey CI, Berven SH, et al: A novel classification system for spinal instability in neoplastic disease: an evidence-based approach and expert consensus from the Spine Oncology Study Group. Spine (Phila Pa 1976) 35:E1221-E1229, 2010

12. Fourney DR, Schomer DF, Nader R, Chlan-Fourney J, Suki D, Ahrar K, et al: Percutaneous vertebroplasty and kyphoplasty for painful vertebral body fractures in cancer patients. J Neurosurg 98 (1 Suppl):21-30, 2003

13. Gerszten PC, Burton SA, Ozhasoglu C, Welch WC: Radiosurgery for spinal metastases: clinical experience in
500 cases from a single institution. Spine (Phila Pa 1976) 32:193-199, 2007

14. Gerszten PC, Germanwala A, Burton SA, Welch WC, Ozhasoglu C, Vogel WJ: Combination kyphoplasty and spinal radiosurgery: a new treatment paradigm for pathological fractures. J Neurosurg Spine 3:296-301, 2005

15. Gerszten PC, Mendel E, Yamada Y: Radiotherapy and radiosurgery for metastatic spine disease: what are the options, indications, and outcomes? Spine (Phila Pa 1976) 34 (22 Suppl):S78-S92, 2009

16. Jackson JB III, Crimaldi AJ, Peindl R, Norton HJ, Anderson WE, Patt JC: Effect of polyether ether ketone on therapeutic radiation to the spine: a pilot study. Spine (Phila Pa 1976) 42:E1-E7, 2017

17. Kaloostian PE, Yurter A, Zadnik PL, Sciubba DM, Gokaslan ZL: Current paradigms for metastatic spinal disease: an evidence-based review. Ann Surg Oncol 21:248 262,2014

18. Lovelock DM, Zhang Z, Jackson A, Keam J, Bekelman J, Bilsky M, et al: Correlation of local failure with measures of dose insufficiency in the high-dose single-fraction treatment of bony metastases. Int J Radiat Oncol Biol Phys 77:12821287,2010

19. Ma L, Sahgal A, Hossain S, Chuang C, Descovich M, Huang K, et al: Nonrandom intrafraction target motions and general strategy for correction of spine stereotactic body radiotherapy. Int J Radiat Oncol Biol Phys 75:1261-1265, 2009

20. Moussazadeh N, Lis E, Katsoulakis E, Kahn S, Svoboda M, DiStefano NM, et al: Five-year outcomes of high-dose singlefraction spinal stereotactic radiosurgery. Int J Radiat Oncol Biol Phys 93:361-367, 2015

21. Murray JA, Bruels MC, Lindberg RD: Irradiation of polymethylmethacrylate. In vitro gamma radiation effect. J Bone Joint Surg Am 56:311-312, 1974

22. Ortiz Gómez JA: The incidence of vertebral body metastases. Int Orthop 19:309-311, 1995

23. Potters L, Kavanagh B, Galvin JM, Hevezi JM, Janjan NA, Larson DA, et al: American Society for Therapeutic Radiology and Oncology (ASTRO) and American College of Radiology (ACR) practice guideline for the performance of stereotactic body radiation therapy. Int J Radiat Oncol Biol Phys 76:326-332, 2010

24. Puvanesarajah V, Lo SL, Aygun N, Liauw JA, Jusué-Torres I, Lina IA, et al: Prognostic factors associated with pain palliation after spine stereotactic body radiation therapy. J Neurosurg Spine 23:620-629, 2015

25. Redmond KJ, Lo SS, Soltys SG, Yamada Y, Barani IJ, Brown $\mathrm{PD}$, et al: Consensus guidelines for postoperative stereotactic body radiation therapy for spinal metastases: results of an international survey. J Neurosurg Spine 26:299-306, 2017

26. Sahgal A, Roberge D, Schellenberg D, Purdie TG, Swaminath A, Pantarotto J, et al: The Canadian Association of Radiation Oncology scope of practice guidelines for lung, liver and spine stereotactic body radiotherapy. Clin Oncol (R Coll Radiol) 24:629-639, 2012

27. Sahgal A, Weinberg V, Ma L, Chang E, Chao S, Muacevic A, et al: Probabilities of radiation myelopathy specific to stereotactic body radiation therapy to guide safe practice. Int J Radiat Oncol Biol Phys 85:341-347, 2013

28. Sahgal A, Whyne CM, Ma L, Larson DA, Fehlings MG: Vertebral compression fracture after stereotactic body radiotherapy for spinal metastases. Lancet Oncol 14:e310e320, 2013

29. Verellen D, De Ridder M, Linthout N, Tournel K, Soete G, Storme G: Innovations in image-guided radiotherapy. Nat Rev Cancer 7:949-960, 2007

30. Wang XS, Rhines LD, Shiu AS, Yang JN, Selek U, Gning I, et al: Stereotactic body radiation therapy for management of spinal metastases in patients without spinal cord 
compression: a phase 1-2 trial. Lancet Oncol 13:395-402, 2012

31. Weill A, Chiras J, Simon JM, Rose M, Sola-Martinez T, Enkaoua E: Spinal metastases: indications for and results of percutaneous injection of acrylic surgical cement. Radiology 199:241-247, 1996

32. Yamada Y, Bilsky MH, Lovelock DM, Venkatraman ES, Toner S, Johnson J, et al: High-dose, single-fraction imageguided intensity-modulated radiotherapy for metastatic spinal lesions. Int J Radiat Oncol Biol Phys 71:484-490, 2008

33. Yamada Y, Katsoulakis E, Laufer I, Lovelock M, Barzilai O, McLaughlin LA, et al: The impact of histology and delivered dose on local control of spinal metastases treated with stereotactic radiosurgery. Neurosurg Focus 42(1):E6, 2017

\section{Disclosures}

Dr. Lis is a consultant for and has received educational training support from Medtronic. Dr. Yamada is a consultant for Brainlab and Varian Medical Systems and is a member of the Medical Advisory Board of the Chordoma Foundation. Dr. Bilsky is a consultant for Globus and Brainlab and receives royalties from DePuy Synthes. Dr. Laufer is a consultant for DePuy Synthes, Globus, and Spine Wave.

\section{Author Contributions}

Conception and design: Laufer, Barzilai, Yamada, Bilsky. Acquisition of data: all authors. Analysis and interpretation of data: all authors. Drafting the article: Barzilai. Critically revising the article: Laufer, Barzilai, Bilsky. Reviewed submitted version of manuscript: all authors. Approved the final version of the manuscript on behalf of all authors: Laufer. Statistical analysis: Barzilai, DiStefano. Administrative/technical/material support: Barzilai. Study supervision: Laufer, Bilsky.

\section{Correspondence}

Ilya Laufer, Memorial Sloan Kettering Cancer Center, Department of Surgery, Neurosurgery Service, 1275 York Ave., New York, NY 10065. email: lauferi@mskcc.org. 